\title{
A technical appraisal of guidelines for the management of skin rash in patients on chemotherapy and targeted therapy
}

\author{
Fangyuan Zhang ${ }^{1}$, Sumei $\mathrm{Lv}^{2}$, Yating Feng ${ }^{3}$, Xuan Yang ${ }^{1}$ and Wanmin Qiang ${ }^{\text {* }^{*}}$ (D)
}

\begin{abstract}
Background: Skin rash remains one of the most prevalent and troublesome clinical problems experienced by patients on chemotherapy and targeted therapy. To ensure high-quality care, guidelines are seen as the best guidance. Considering the quality of guidelines varies greatly, a systematical appraisal of the methodological quality of guidelines for the management of skin rash in patients on chemotherapeutic drugs and targeted anticancer therapies was undertaken, in order to identify appropriate ones for healthcare professionals.

Methods: A systematic search of databases and Internet was conducted to obtain pertinent guidelines. Two reviewers independently assessed the eligibility of guidelines according to the inclusion criteria. Then the guidelines included were appraised by three researchers with the methodological quality of eligible guideline using Appraisal of Guidelines for Research and Evaluation II (AGREEII).

Results: Totally nineteen guidelines met the inclusion criteria. The quality ranged from good to acceptable in scope and purpose (mean: $78.80 \%$, range: $66.67-94.44 \%$ ) and clarity of presentation domains (mean: 85.38\%, $75.00-$ 91.67\%), but not in stakeholder involvement (mean: 50.15\%, range: $36.11-75.00 \%)$, rigor of development (mean: 23.65\%, range: 6.25-70.83\%), applicability (mean: 23.96\%, range: 4.17-52.08\%), and editorial independence domains (mean: 45.18\%, range: 0.00-87.50\%). Overall, two guidelines were classified as "recommended".

Conclusions: Only two guidelines were recommended to manage skin rash in patients on chemotherapy and targeted therapies, most guidelines issued were of low to moderate quality. Thus, more attention should be paid to the methodological quality of guideline development in this field.
\end{abstract}

Keywords: Chemotherapy, Targeted therapy, Rash, Guidelines, AGREE

\section{Background}

More than one hundred kinds of drugs are widely used in the clinical treatment of different cancers, and they can be divided into non-targeted agents and targeted agents [1]. Although conventional chemotherapy remains an essential mainstay of cancer treatment, targeted drugs are increasingly being applied to treat cancer because of better tolerance. Due to the disturbance of specific cell cycle phases and target molecules are present in the skin, skin reactions are common side effects of many classic chemotherapeutic agents and the newer molecular targeted therapies [2-4].

\footnotetext{
* Correspondence: wmqiang213@126.com

${ }^{1}$ Tianjin Medical University Cancer Institute and Hospital, National Clinical Research Center for Cancer, Hexi District, 1 West Lake Road, Tianjin, CN, China

Full list of author information is available at the end of the article
}

The incidence of skin reactions varies in cancer patients according to the chemotherapeutic agents used, and would increase when together with targeted therapies $[5,6]$. The cutaneous adverse events of conventional chemotherapy and targeted therapies could have a negative impact on patients' physical, psychological and social well-being, and frequently cause dose reduction and delay, or even discontinuation of treatment [7-9]. Skin rash acts as one of the most common dermatological toxicities, appropriate management strategies are necessary to improve health-related quality of life and outcomes of patients on chemotherapeutic drugs and targeted anticancer therapies [1].

Clinical practice guidelines ('guidelines') are defined as the systematically developed statements to assist practitioner and patient decisions about appropriate health care 
for specific clinical circumstances by the Institute of Medicine (IOM) [10]. Many scientific societies and specialist groups have developed and issued guidelines for the management of skin rash in patients on chemotherapy and targeted therapy, in order to rationalize and standardize the clinical practice. However, the value of guidelines is proportional to the quality of the guidelines, flawed guidelines may result in the promotion of ineffective, or even harmful practices to patients, and a waste of limited healthcare resources [11, 12]. Efforts are greatly desired to evaluate the methodological quality of guidelines before application to clinical practice. Thus, we conducted this study to appraise the methodological quality of guidelines for the management of skin rash in patients on chemotherapy and targeted therapy, and to identify appropriate guidelines for healthcare professionals to provide better quality care for patients.

\section{Methods}

\section{Electronic database searches}

A systematic literature search was performed. PubMed and Embase were searched to identify all possible guidelines. Articles published in English between the inception of each database and October 2018, were searched for controlled vocabulary terms specific to each database related to neoplasms, skin toxicity, rash, guidelines. Detailed search strategies were provided in Supplementary Methods (Additional file 1) [13]. We also manually reviewed the references of the included studies.

\section{Internet searches}

Besides, a through internet search was conducted to identify pertinent guidelines from the website of the international cancer organizations and guideline clearinghouses. The guideline resource section in each website was carefully reviewed or searched, and any relevant guidelines were included. A list of these organizations and clearinghouses was shown in Supplementary Methods (Additional file 2).

\section{Eligibility criteria}

We included guidelines according to the following criteria: (1) Target population: Adults patients with cancer, there were no restrictions on type, stage, or site of cancer; (2) Scope: Management strategies of skin rash in patients on chemotherapeutic drugs and targeted therapy, included prophylaxis, assessment, pharmaceutical or nonpharmaceutical treatment; (3) Development method: Guidelines were developed based on evidence, consensus and/or expert opinion; (4) Development organization: Guidelines were developed by regional, national or international professional organization or societies, or by a national or international expert panel; (5) Form: Full texts available; (6) Others: If there had updated versions, only the latest one was included. Protocol, interpretation and translation of guidelines were excluded.

\section{Guideline selection}

After removing duplicate records, two researchers (YT, YX) independently assessed the eligibility of all guidelines. Disagreements regarding inclusion in the final review were resolved through discussion and consensus. A third researcher (WM) was consulted if disagreement cannot be resolved between the two researchers. Besides, the guidelines included were classified into two types: evidence-based guidelines (EBGs) and consensus-based guidelines (CBGs) [14]. If a guideline reported a search strategy, the quality of evidence on which a recommendation is based and grading of recommendation, then this guideline is judged as EBG. CBG is defined as a document representing the collective opinion of an expert panel without illustrating the source of evidence or grading of recommendation.

\section{Quality appraisal}

The Appraisal of Guidelines for Research and Evaluation II (AGREEII) tool was used to critique the guidelines. AGREEII is a guideline quality appraisal tool with high construct validity, which consists of 23 items arranged into 6 domains: scope and purpose (3 items), stakeholder involvement (3 items), rigor of development (8 items), clarity of presentation (3 items), applicability (4 items), and editorial independence ( 2 items) $[15,16]$. Each item is scored between strongly agree (7) and strongly disagree (1). The items scores within a domain were then added and calculated as a percentage. A domain was determined to be effectively addressed if its score was $\geq 60 \%$ [17-20]. All members of the research team undertook a training review process to ensure consistency and reliability in grading. Assessment of all the included guidelines was performed independently by three researchers (FY, SM and WM). Prior to the formal assessment, we conducted a pre-assessment by randomly choosing five guidelines. The intra-class correlation coefficients (ICCs) were calculated to assess the intra-rater reliability of the three appraisers. Only when ICC was more than 0.80 , the formal assessment would start.

Overall guideline assessment reached consensus according to the quality of the guideline. Each guideline was classified as "recommended", "recommended with modifications" or "not recommended".

\section{Results}

\section{Guidelines included}

A total of 710 references were identified from electronic databases, international cancer organizations and guideline clearinghouses. Of these, 458 were excluded by screening the title and abstract, and 26 were excluded by 
reviewing the full texts of potentially eligible articles. Finally, 19 guidelines were included in this review (Fig. 1) [21-39]. The characteristics of the included guidelines are presented in Table 1. All guidelines included were developed by an interdisciplinary expert panel, in which there were five guidelines issued by specific society or organization focused on adverse events caused by chemotherapy or targeted therapy. As for the methodology of guideline development, only two guidelines were judged as EBG.

\section{Quality appraisal \\ Overall quality}

Table 2 shows the standardized domain scores of each included guideline and their overall assessment. The quality of guidelines varied greatly, from fulfilling most of the AGREEII criteria to fulfilling only two. Among six domains, only two domains of "scope and purpose" and "clarity and presentation" scored over $60 \%$. Overall, two guidelines (10.53\%) were classified as "recommended", ten guidelines $(52.63 \%)$ were "recommended with modification", while the rest (36.84\%) were "not recommended".

Scope and purpose The median score for the scope and purpose domain was $78.80 \%$ (range: $66.67-94.44 \%$ ). Most guidelines clearly described overall objectives, health questions and target populations.

Stakeholder involvement The median score for the stakeholder involvement domain was $50.15 \%$ (range: 36.11-75.00\%). Only the UK 2009 guideline scored above $60 \%$ [24]. No guidelines clearly described their numbers' roles in the guideline development process. Besides, methodology experts and economists were not included in any guidelines. Only one guideline reported consideration of the views and preferences of patient representative (UK 2009) [24].

Rigor of development The median score for the rigor of development domain was 23.65\% (range: 6.2570.83\%). Only STSG 2011 and ONS 2017 scored over $60 \%$, as they used systematic methods of searching for evidence and for formulating recommendations [27, 39]. Only Canada 2012 clearly described methods for conducting external reviews [31]; only ONS 2017 described their procedures for updating guidelines [39].

Clarity of presentation The median score in this domain was $85.38 \%$ (range: $75.00-91.67 \%$ ), with all guidelines scoring over $60 \%$. All of the guidelines included could provide specific, unambiguous and easily identifiable recommendations.

Applicability The median score for the applicability domain was $23.96 \%$ (range: $4.17-52.08 \%$ ), with no guideline scoring over $60 \%$. Almost all of the guidelines failed to describe the facilitators and barriers of their applications and did not sufficiently consider the costs of applying their recommendations.

Editorial Independence The median score for the editorial independence domain was $45.18 \%$ (range: $0.00-$ $87.50 \%$ ), with six guidelines scoring above $60 \%$. Most guidelines failed to report a statement of "the views or

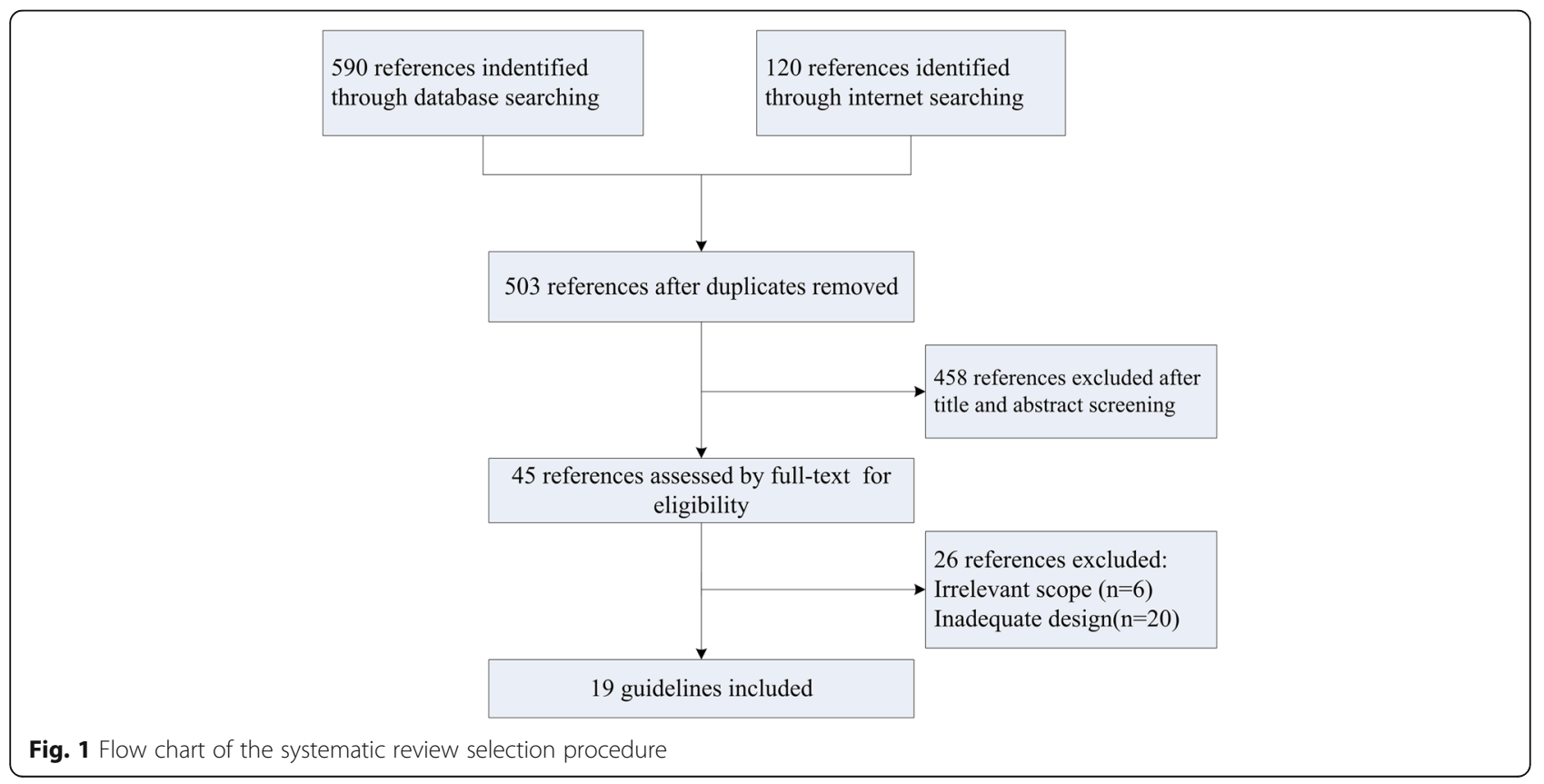




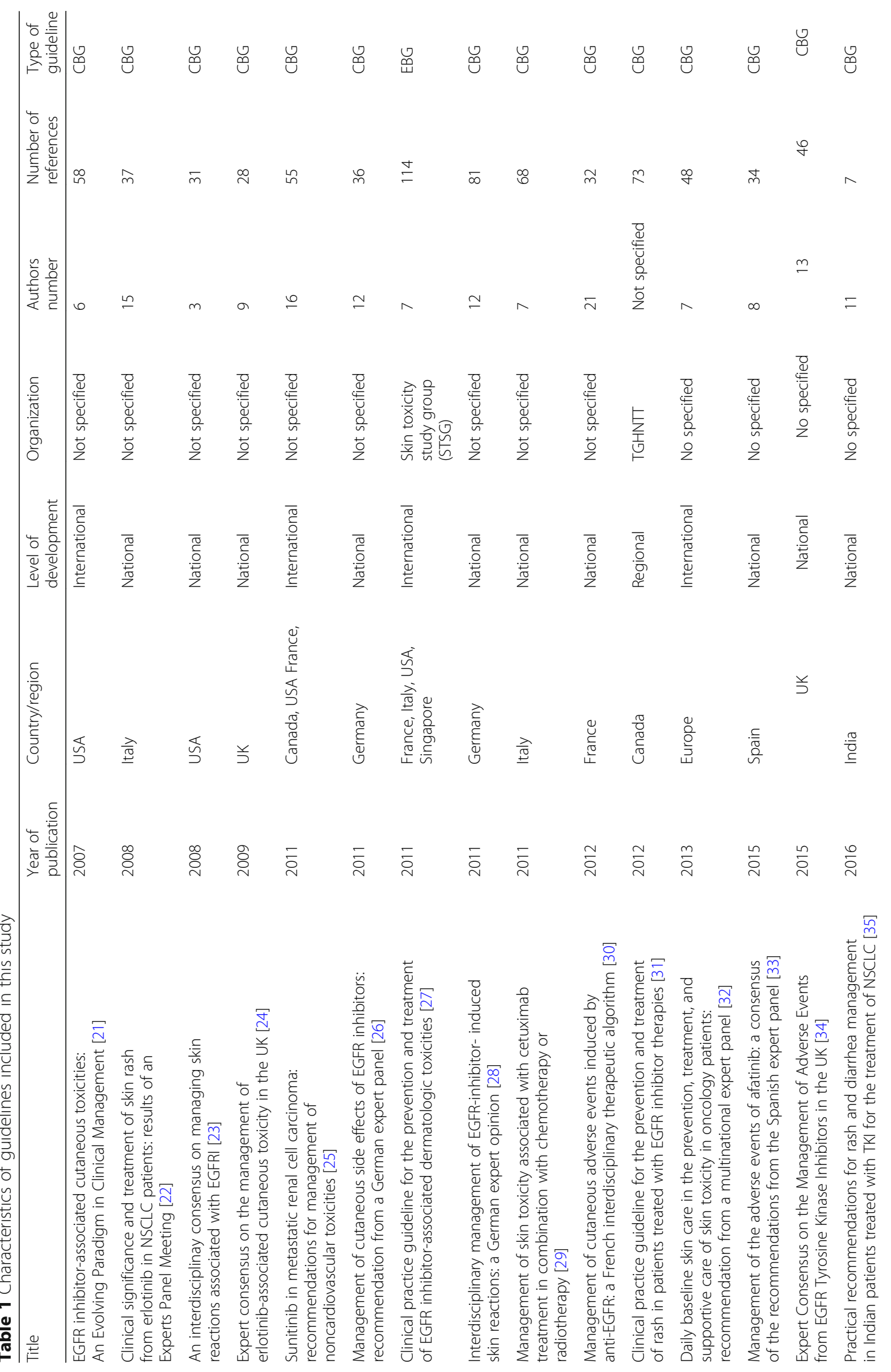




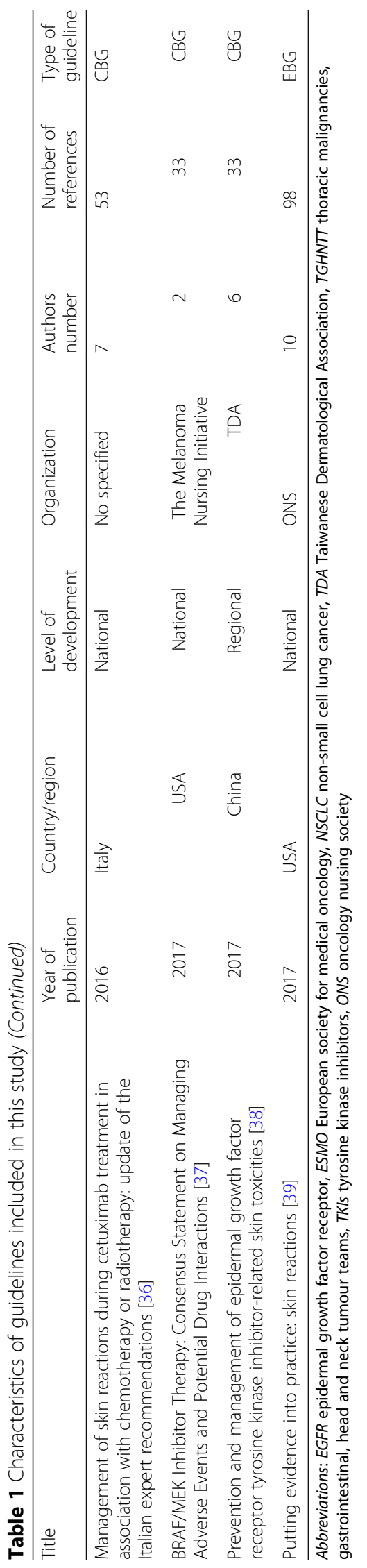


Table 2 Standardized domain scores (\%) and overall assessment ( $N=19)$

\begin{tabular}{|c|c|c|c|c|c|c|c|}
\hline Guidelines & $\begin{array}{l}\text { Scope and } \\
\text { purpose }\end{array}$ & $\begin{array}{l}\text { Stakeholder } \\
\text { involvement }\end{array}$ & $\begin{array}{l}\text { Rigor of } \\
\text { development }\end{array}$ & $\begin{array}{l}\text { Clarity of } \\
\text { presentation }\end{array}$ & Applicability & $\begin{array}{l}\text { Editorial } \\
\text { independence }\end{array}$ & $\begin{array}{l}\text { Overall } \\
\text { assessment }\end{array}$ \\
\hline USA 2007 [21] & 77.78 & 50.00 & 7.29 & 80.56 & 24.75 & 29.17 & Not recommended \\
\hline Italy 2008 [22] & 75.00 & 47.22 & 6.25 & 88.89 & 23.33 & 8.33 & Not recommended \\
\hline USA 2008 [23] & 80.56 & 52.78 & 9.38 & 83.33 & 14.58 & 29.17 & Not recommended \\
\hline UK 2009 [24] & 80.56 & 75.00 & 17.71 & 91.67 & 25.42 & 20.83 & Not recommended \\
\hline International 2011 [25] & 69.44 & 50.00 & 19.79 & 80.56 & 29.17 & 70.83 & $\begin{array}{l}\text { Recommended with } \\
\text { modifications }\end{array}$ \\
\hline Germany 2011 [26] & 69.44 & 41.67 & 6.25 & 75.00 & 10.42 & 25.00 & Not recommended \\
\hline STSG 2011 [27] & 69.44 & 52.78 & 61.67 & 91.67 & 52.08 & 66.67 & Recommended \\
\hline Germany 2011 [28] & 66.67 & 44.44 & 25.00 & 88.89 & 20.83 & 87.50 & $\begin{array}{l}\text { Recommended with } \\
\text { modifications }\end{array}$ \\
\hline Italy 2011 [29] & 80.56 & 50.00 & 19.58 & 88.89 & 20.83 & 20.83 & Not recommended \\
\hline France 2012 [30] & 86.11 & 50.00 & 52.08 & 83.33 & 22.92 & 0.00 & $\begin{array}{l}\text { Recommended with } \\
\text { modifications }\end{array}$ \\
\hline Canada 2012 [31] & 83.33 & 55.56 & 45.83 & 80.56 & 35.42 & 83.33 & $\begin{array}{l}\text { Recommended with } \\
\text { modifications }\end{array}$ \\
\hline Europe 2013 [32] & 83.33 & 52.78 & 25.00 & 77.78 & 21.25 & 58.33 & $\begin{array}{l}\text { Recommended with } \\
\text { modifications }\end{array}$ \\
\hline Spain 2015 [33] & 83.33 & 58.33 & 12.50 & 88.89 & 25.50 & 50.00 & $\begin{array}{l}\text { Recommended with } \\
\text { modifications }\end{array}$ \\
\hline UK 2015 [34] & 80.56 & 50.00 & 17.71 & 91.67 & 25.42 & 66.67 & $\begin{array}{l}\text { Recommended with } \\
\text { modifications }\end{array}$ \\
\hline India 2016 [35] & 83.33 & 36.11 & 8.33 & 88.89 & 21.67 & 54.17 & $\begin{array}{l}\text { Recommended with } \\
\text { modifications }\end{array}$ \\
\hline Italy 2016 [36] & 80.56 & 50.00 & 25.42 & 86.11 & 22.92 & 0.00 & Not recommended \\
\hline USA 2017 [37] & 83.33 & 36.11 & 8.33 & 88.89 & 21.67 & 54.17 & $\begin{array}{l}\text { Recommended with } \\
\text { modifications }\end{array}$ \\
\hline China 2017 [38] & 69.44 & 50.00 & 10.42 & 77.78 & 4.17 & 75.00 & $\begin{array}{l}\text { Recommended with } \\
\text { modifications }\end{array}$ \\
\hline ONS 2017 [39] & 94.44 & 50.00 & 70.83 & 88.89 & 32.92 & 58.33 & Recommended \\
\hline Median & 78.80 & 50.15 & 23.65 & 85.38 & 23.96 & 45.18 & \\
\hline
\end{tabular}

interests of the funding body have not influenced the final consensus or recommendations" or a "no funding" statement.

\section{Discussions}

\section{Characteristics of included guidelines}

The first guideline on the management of skin rash in patients on chemotherapy and targeted therapy was published in 2007. Since than, the number had grown rapidly, up to 19 guidelines in 2018. However, lots of guidelines were judged as CBG, as their recommedations were formed by expert opinion or literature review, but did not provide rating of both the quality of the evidence and strength of the recommendations, which made them less trustworthy. Thus, in order to ensure that guidelines are of a high methodological quality, it is essential to follow a evidence-based guideline development standard, such as the Grading of Recommendations Assessment, Development and Evaluation (GRADE) [40].

\section{Quality of the guidelines}

Of 19 guidelines included, moderate to high scores were achieved in domains of "clarity of presentation", "scope and purpose", and "stakeholder involvement". Mean scores for domian of "applicability" were the lowest, showed that a gap currently exists between the evidence provided and its applicability in the clinical setting, and was in contrast with the need for clarity and user friendliness advocated by some authors [41-43]. Regarding the domain of "rigor of development" with the second lowest mean scores, most guidelines were not based on a systematic review of the literature and were lack of grading of the level of evidence and recommendations, and did not provide recommendations explicitly linked to evidence, which would lower target users' confidence [17]. Information on "editorial independence", the most common source of bias in guideline development, was particularly important, but was neglected in most guidelines, which might be associated with differences in recommendations 
$[44,45]$. As a result, only two guidelines met the criteria of AGREEII and were ranked as "recommended", which meaned that the rest were of a great room to improve the methodological quality, and we should be cautious when application.

\section{Suggestions to improve guideline's quality}

First of all, professional organizations or socities at national or international level should take responsibility and produce fewer but more trustworthy guidelines based on evidence, in order to avoid a potential waste of scarce guidelines development resources [40]. Then, a panel of multidisciplinary experts should be founded, especially methodology experts shold be included. The most important part is that developers should comply with the definition of guideline by IOM and evidence-based guideline development standard, such as standards from SIGN and NICE [46]. A critcial appraisal of guideline using AGREEII should be considered before release, to make sure if quality standards are met. Furthermore, journal editors ought to set higher standards for peer review, only those guidelines of high quality could be considered for publication [44]. What is more, developers need to update guidelines regularly, and the process should follow the standard of the Guidelines International Network Updating Guidelines Working Group, as it could minimize the risk of bias when update [47].

\section{Strengths and limitations}

This is the first study to systematically review all available guidelines of the management of skin rash in patients on chemotherapy and targeted therapy, with the aim to screen guidelines with high quality, and provide healthcare professionals with evidence-based rocommendations to manage skin rash. We have performed a comprehensive search to identify relevent guidelines, and adopted wellaccepted AGREEII to appraise the methodological quality and derive overall assessment of the guidelines.

Although AGREEII appears to be the best methodological tool available, it does not consider the relative importance of six domains of quality. This suggests that the domains of AGREEII should not be weighed equally, such as the domain of "rigor of development" should be of more weight $[17,48]$. Besides, the AGREE instrument is developed both for quality assessment and report [49]. Especially for the domain of "editorial independence", we would consider that low scores in this domain may not reflect a real influence of the funding body in the guidelines development process, but rather reflect an insufficient or a not very explicit reporting of potential conflicts of interest. However, it is impossible to find if the authors chose not to disclose such conflicts [14]. Moreover, guidelines only in English were included, eligible guidelines in other languages were possible missed.

\section{Conclusions}

Only two guidelines were recommended to manage skin rash in patients on chemotherapy and targeted therapy, most guidelines issued were of low to moderate quality. More attention should be paid on the methodological quality of guideline development in this field, particularly in the domains of "rigor of development", "applicability", and "editorial independence".

\section{Supplementary information}

Supplementary information accompanies this paper at https://doi.org/10. 1186/s12913-019-4539-6.

Additional file 1. Search method.

Additional file 2. Internet list.

\section{Abbreviations}

AGREE: Appraisal of guidelines for research and evaluation tool; CBE: Consensus-based guideline; CRR: Chemotherapy related rash; EBG: Evidence-based guideline; EGFR: Epidermal growth factor receptor; ESMO: European society for medical oncology; NSCLC: Non-small cell lung cancer; ONS: Oncology nursing society; TDA: Taiwanese Dermatological Association; TGHNTT: Thoracic malignancies, gastrointestinal, head and neck tumour teams; TKIs: Tyrosine kinase inhibitors

\section{Acknowledgements}

We thank Chinese Anti-Cancer Association Oncologic Nursing Committee who offering great support for the development of this review.

\section{Authors' contributions \\ FY contributed to the study protocol, defined the search strategy, performed the literature search, contributed to the review of the papers for inclusion, quality assessment and data analysis, and drafted the manuscript. YT and YX participated in the literature search, reviewed the papers for inclusion. SM participated in the quality assessment of included systematic reviews. WM participated in the study protocol, defined the search strategy, and helped draft the manuscript. All authors read and approved the final manuscript.}

\section{Funding}

The authors received no special funding for this work.

Availability of data and materials

All data generated or analysed during this study are included in this published article.

Ethics approval and consent to participate

Not applicable: a critical review of guidelines.

Consent for publication

Not applicable: no individual person's data.

Competing interests

The authors declare that they have no competing interest.

\section{Author details}

${ }^{1}$ Tianjin Medical University Cancer Institute and Hospital, National Clinical Research Center for Cancer, Hexi District, 1 West Lake Road, Tianjin, CN, China. ${ }^{2}$ Forth Hospital of Hebei Medical University, Shijiazhuang, Hebei, China. ${ }^{3}$ The First Affiliated Hospital of Zhengzhou University, Zhengzhou, Henan, China. 


\section{Received: 5 April 2019 Accepted: 16 September 2019} Published online: 16 October 2019

\section{References}

1. Baldo BA, Pham NH. Adverse reactions to targeted and non-targeted chemotherapeutic drugs with emphasis on hypersensitivity responses and the invasive metastatic switch. Cancer Metastasis Rev. 2013;32(3-4):723-61.

2. Reyes-Habito CM, Roh EK. Cutaneous reactions to chemotherapeutic drugs and targeted therapies for cancer: part I. conventional chemotherapeutic drugs. J Am Acad Dermatol. 2014;71(2):201-3 215-216.

3. Reyes-Habito CM, Roh EK. Cutaneous reactions to chemotherapeutic drugs and targeted therapy for cancer: part II. Targeted therapy. J Am Acad Dermatol. 2014:71(2):211-7 227-228.

4. Payne AS, James WD, Weiss RB. Dermatologic toxicity of chemotherapeutic agents. Semin Oncol. 2006:33(1):86-97.

5. Zhang X, Ran YG, Wang KJ. Risk of severe rash in cancer patients treated with EGFR tyrosine kinase inhibitors: a systematic review and meta-analysis. Future Oncol. 2016;12(23):2741-53.

6. Wollenberg A, Kroth J, Hauschild A, et al. Cutaneous side effects of EGFR inhibitors-appearance and management. Dtsch Med Wochenschr. 2010;135(4):149-54.

7. Miller KK, Gorcey L, Mclellan BN. Chemotherapy-induced hand-foot syndrome and nail changes: a review of clinical presentation, etiology, pathogenesis, and management. J Am Acad Dermatol. 2014;71(4):787-94.

8. Koukakis R, Gatta F, Hechmati G, Siena S. Skin toxicity and quality of life during treatment with panitumumab for RAS wild-type metastatic colorectal carcinoma: results from three randomised clinical trials. Qual Life Res. 2016:25(10):2645-56.

9. Macdonald JB, Macdonald B, Golitz LE, LoRusso P, Sekulic A. Cutaneous adverse effects of targeted therapies: part I: inhibitors of the cellular membrane. J Am Acad Dermatol. 2015;72(2):203-18 203-218.

10. Committee to Advise the Public Health Service on Clinical Practice Guidelines IoM. Clinical practice guidelines: directions for a new program. Washington: National Academy Press; 1990.

11. Shaneyfelt TM, Mayo-Smith MF, Rothwangl J. Are guidelines following guidelines? The methodological quality of clinical practice guidelines in the peer-reviewed medical literature. JAMA. 1999:281(20):1900-5.

12. Grilli R, Magrini N, Penna A, Mura G, Liberati A. Practice guidelines developed by specialty societies: the need for a critical appraisal. Lancet 2000;355(9198):103-6.

13. Zhang F, Shen A, Jin Y, Qiang W. The management strategies of cancerassociated anorexia: a critical appraisal of systematic reviews. BMC Complement Altern Med. 2018;18(1):236.

14. Jin $Y$, Wang $Y$, Zhang $Y$, et al. Nursing practice guidelines in China do need reform: a critical appraisal using the AGREE II instrument. Worldviews EvidBased Nurs. 2016:13(2):124-38.

15. Brouwers MC, Kho ME, Browman GP, et al. AGREE Il: advancing guideline development, reporting, and evaluation in health care. Prev Med. 2010:51(5):421-4

16. Dans AL, Dans LF. Appraising a tool for guideline appraisal (the AGREE I instrument). J Clin Epidemiol. 2010;63(12):1281-2.

17. Chiappini E, Bortone B, Galli L, Martino MD. Guidelines for the symptomatic management of fever in children: systematic review of the literature and quality appraisal with AGREE II. BMJ Open. 2017;7(7):e15404.

18. Bragge P, Pattuwage L, Marshall S, et al. Quality of guidelines for cognitive rehabilitation following traumatic brain injury. J Head Trauma Rehab. 2014; 29(4):277-89.

19. Ríos E, Serón P, Lanas F, Bonfill X, Quigley EMM, Alonso-Coello P. Evaluation of the quality of clinical practice guidelines for the management of esophageal or gastric variceal bleeding. Eur J Gastroen Hepat. 2014;26(4):422-31.

20. National Institute for Health and Care Excellence (NICE). Developing NICE Guidelines: The Manual. London; 2015.

21. Lynch TJ, Kim ES, Eaby B, Garey J, West DP, Lacouture ME. Epidermal growth factor receptor inhibitor-associated cutaneous toxicities: an evolving paradigm in clinical management. Oncologist. 2007;12(5):610-21.

22. Gridelli C, Maione P, Amoroso D, et al. Clinical significance and treatment of skin rash from erlotinib in non-small cell lung cancer patients: results of an experts panel meeting. Crit Rev Oncol Hematol. 2008;66(2):155-62.

23. Eaby B, Culkin A, Lacouture ME. An interdisciplinary consensus on managing skin reactions associated with human epidermal growth factor receptor inhibitors. Clin J Oncol Nurs. 2008;12(2):283-90.

24. Thatcher N, Nicolson M, Groves RW, et al. Expert consensus on the Management of Erlotinib-Associated Cutaneous Toxicity in the U.K. Oncologist. 2009;14(8):840-7.
25. Kollmannsberger $C$, Bjarnason $G$, Burnett $P$, et al. Sunitinib in metastatic renal cell carcinoma: recommendations for management of noncardiovascular toxicities. Oncologist. 2011;16(5):543-53.

26. Gutzmer R, Becker JC, Enk A, et al. Management of cutaneous side effects of EGFR inhibitors: recommendations from a German expert panel for the primary treating physician. J Dtsch Dermatol Ges. 2011;9(3):195-202.

27. Lacouture ME, Anadkat MJ, Bensadoun R, et al. Clinical practice guidelines for the prevention and treatment of EGFR inhibitor-associated dermatologic toxicities. Support Care Cancer. 2011;19(8):1079-95.

28. Potthoff K, Hofheinz R, Hassel JC, et al. Interdisciplinary management of EGFR-inhibitor-induced skin reactions: a German expert opinion. Ann Oncol. 2011;22(3):524-35.

29. Pinto C, Barone CA, Girolomoni G, et al. Management of Skin Toxicity Associated with Cetuximab treatment in combination with chemotherapy or radiotherapy. Oncologist. 2011;16(2):228-38.

30. Reguiai Z, Bachet JB, Bachmeyer C, et al. Management of cutaneous adverse events induced by anti-EGFR (epidermal growth factor receptor): a French interdisciplinary therapeutic algorithm. Support Care Cancer. 2012;20(7):1395-404.

31. Alberta Provincial Thoracic Malignancies Team, Alberta Provincial Gastrointestinal Tumour Team, Alberta Provincial Head and Neck Tumour Team. Prevention and treatment of rash in patients treated with EGFR inhibitor therapies. Edmonton: CancerControl Alberta; 2012. p. 15. (Clinical practice guideline; no. SUPP-003)

32. Bensadoun RJ, Humbert P, Krutman J, et al. Daily baseline skin care in the prevention, treatment, and supportive care of skin toxicity in oncology patients: recommendations from a multinational expert panel. Cancer Manag Res. 2013;5:401-8.

33. Arriola E, Reguart N, Artal A, et al. Management of the adverse events of afatinib: a consensus of the recommendations of the Spanish expert panel. Future Oncol. 2015;11(2):267-77.

34. Califano R, Tariq N, Compton S, Fitzgerald DA, Harwood CA, et al. Expert consensus on the Management of Adverse Events from EGFR tyrosine kinase inhibitors in the UK. Drugs. 2015;75(12):1335-48.

35. Parikh P, Prabhash $K$, Naik R, et al. Practical recommendation for rash and diarrhea management in Indian patients treated with tyrosine kinase inhibitors for the treatment of non-small cell lung cancer. Indian J Cancer. 2016:53(1):87

36. Pinto C, Barone CA, Girolomoni G, et al. Management of Skin Reactions during Cetuximab Treatment in association with chemotherapy or radiotherapy. Am J Clin Oncol. 2016:39(4):407-15.

37. Czupryn M, Cisneros J. BRAF/MEK inhibitor therapy: consensus statement from the Faculty of the Melanoma Nursing Initiative on managing adverse events and potential drug interactions[J]. Clin J Oncol Nurs. 2017;21(4 Suppl):11-29.

38. Chu CY, Chen KY, Chang J, Wei YF, Lee CH, et al. Taiwanese dermatological association consensus for the prevention and management of epidermal growth factor receptor tyrosine kinase inhibitor-related skin toxicities[J]. J Formos Med Assoc. 2017;116(6):413-23.

39. Oncology Nursing Society. Putting Evidence into Practice: Skin Reactions: 2017. https://www.ons.org/practice-resources/pep/skin-reactions.

40. Shekelle PG. Clinical practice guidelines What's next? JAMA. 2018;320(8):757-8.

41. Brouwers MC, Kho ME, Browman GP, et al. Development of the AGREE II, part 2: assessment of validity of items and tools to support application. CMAJ. 2010;182(10):E472-8.

42. Cavazos JM, Naik AD, Woofter A, Abraham NS. Barriers to physician adherence to nonsteroidal anti-inflammatory drug guidelines: a qualitative study. Aliment Pharmacol Ther. 2008;28(6):789-98.

43. Cabana MD, Rand CS, Powe NR, et al. Why don't physicians follow clinical practice guidelines? A framework for improvement. JAMA. 1999;282(15): 1458-65 https://jamanetwork.com/journals/jama/article-abstract/192017.

44. Larenas-Linnemann DES, Antolín-Amérigo D, Parisi C, et al. National clinical practice guidelines for allergen immunotherapy: an international assessment applying AGREE-II. Allergy. 2018;73(3):664-72.

45. Sox HC. Conflict of interest in practice guidelines panels. JAMA. 2017; 317(17):1739-40

46. About the Updating GuidelinesWorking Group. Guidelines International Network website. http://www.g-i-n.net/working-groups/updatingguidelines/about. Updated April 13, 2016. Accessed 19 Jan 2019.

47. Grol R, Cluzeau FA, Burgers JS. Clinical practice guidelines: towards better quality guidelines and increased international collaboration. $\mathrm{Br} J$ Cancer. 2003;89(Suppl 1):S4-8. 
48. Holmer HK, Ogden LA, Burda BU, Norris SL. Quality of clinical practice guidelines for glycemic control in type 2 diabetes mellitus. PLoS One. 2013; 8(4):e58625.

49. Chen YL, Yang KH, Marusic A, Qaseem A, Meerpohl JJ, et al. A reporting tool for practice guidelines in health care: the RIGHT statement[J]. Ann Intern Med. 2017;166(2):128-32

\section{Publisher's Note}

Springer Nature remains neutral with regard to jurisdictional claims in published maps and institutional affiliations.

Ready to submit your research? Choose BMC and benefit from:

- fast, convenient online submission

- thorough peer review by experienced researchers in your field

- rapid publication on acceptance

- support for research data, including large and complex data types

- gold Open Access which fosters wider collaboration and increased citations

- maximum visibility for your research: over $100 \mathrm{M}$ website views per year

At BMC, research is always in progress.

Learn more biomedcentral.com/submissions 